\title{
DcR3 combined with hematological traits serves as a valuable biomarker for the diagnosis of cancer metastasis
}

\author{
Junxin Li ${ }^{1,2, *}$, Ni Xie ${ }^{3, *}$, Jianhui Yuan ${ }^{4, *}$, Lvyan Liu ${ }^{1}$, Qiming Zhou5 ${ }^{5}$ Xiaohu Ren ${ }^{4}$, Qian \\ Chen $^{1,2}$, Guizhong Zhang ${ }^{1}$, Qingguo Ruann ${ }^{1}$, Youhai H. Chen ${ }^{6}$ and Xiaochun Wan ${ }^{1}$ \\ ${ }^{1}$ Shenzhen Laboratory of Fully Human Antibody Engineering, Institute of Biomedicine and Biotechnology, Shenzhen Institutes \\ of Advanced Technology, Chinese Academy of Sciences, University City of Shenzhen, Xili Nanshan, Shenzhen, 518055, P.R. \\ China \\ ${ }^{2}$ University of Chinese Academy of Sciences, Beijing, 100049, P.R. China \\ ${ }^{3}$ Institute of Translation Medicine, Shenzhen Second People's Hospital, Shenzhen, 518035, P.R. China \\ ${ }^{4}$ Institute of Toxicology, Shenzhen Center for Disease Control and Prevention, Shenzhen, 518055, P.R. China \\ ${ }^{5}$ Department of Oncology, Nanshan Hospital of Shenzhen, Shenzhen, 518055, P.R. China \\ ${ }^{6}$ Department of Pathology and Laboratory Medicine, University of Pennsylvania School of Medicine, Philadelphia, PA, 19104, \\ USA \\ *These authors contributed equally to this work
}

Correspondence to: Xiaochun Wan, email: xc.wan@siat.ac.cn

Keywords: DCR3; PDW; HGB; HCT; metastasis

Received: August 09, $2017 \quad$ Accepted: October 30, $2017 \quad$ Published: November 20, 2017

Copyright: Li et al. This is an open-access article distributed under the terms of the Creative Commons Attribution License 3.0 (CC BY 3.0), which permits unrestricted use, distribution, and reproduction in any medium, provided the original author and source are credited.

\section{ABSTRACT}

Decoy receptor 3 (DcR3) is abnormally up-regulated in many cancer cells. It may help cancer cells to escape from immune surveillance and establish metastatic lesions. However, whether DcR3 can be used as a biomarker for the diagnosis of cancer metastasis is unclear. In this study, sera from healthy controls and patients with different cancers were collected, and tested for their DcR3 levels by ELISA. Significantly elevated DcR3 levels were observed in the sera of patients with gastric cancer (2.04 $\pm 1.01, P=0.0061)$, lymphoma $(1.62 \pm 0.75, P=0.041)$, and breast cancer $(1.53 \pm 0.51, P=0.023)$. DCR3 was found to be a suitable biomarker for identifying gastric cancer patients. Importantly, DCR3 was positively associated with platelet distribution width (PDW) $\left(P=2.45 \times 10^{-6}, R=0.63\right)$ in metastatic cancers but negatively associated with hemoglobin (HGB) $(P=0.002, R=-0.59)$ and hematocrit (HCT) $(P=0.001, R=-0.62)$ in non-metastatic cancers. Combined with PDW, HGB and HCT, serum DcR3 could be used to predict the occurrence of cancer metastasis. These findings indicate that DCR3 could be used as a biomarker for the diagnosis of gastric cancer, and for cancer metastasis in combination with hematological traits.

\section{INTRODUCTION}

Decoy receptor 3 (DcR3), also known as tumor necrosis factor receptor superfamily member $6 \mathrm{~B}$ (TNFRSF6B), is a soluble protein that competitively binds Fas ligand [1]. DcR3 has an anti-apoptotic role and is highly expressed in malignant tumors, such as gastric carcinomas [2], liver cancer [3], and breast infiltrating ductal carcinoma (IDC) [4]. DcR3 has been found to be a pleiotropic immune-modulator, and was proposed to serve as a biomarker for inflammatory diseases and cancer $[5,6]$. It was also considered to be a novel prognostic biomarker for small intestinal neuroendocrine tumors [7]. In addition, a considerable amount of evidence suggests that serum DcR3 may have a predictive value for stage $\mathrm{pN} 2$ and the prognosis (TNM classification) of both pancreatic carcinoma and gastric cancer [8, 9]. Recently, we found that DcR3 promoted hepatoma cell migration by downregulating 
E-cadherin expression [10]. Therefore, DcR3 expression may also be closely related to cancer metastasis.

Hematological traits are important clinical parameters and closely related to malignancies such as colorectal cancer [11]. Platelet distribution width (PDW) is an index describing variations in platelet size and is used in differential diagnoses of thrombocytopenia. In recent years, increasing studies have shown that PDW is a diagnostic or prognostic indicator for various cancers, such as colorectal cancer [12], gastric cancer [13], and thyroid cancer [14]. It was reported that the combined detection of PDW and CEA is valuable in differentiating gastric cancer from gastric ulcer and controls [15]. Hematocrit (HCT) is the percentage of red blood cells in blood by volume. Abnormally reduced HCT and hemoglobin (HGB) levels can indicate anemia in patients [16]. Since anemia is closely related to a worse prognosis in cancer patients [17], HCT and HGB could be used as prognostic parameters $[16,18]$. Nevertheless, the association between hematological traits and cancer metastasis has not been studied.

Metastasis is a major cause of mortality in cancer patients. Tumor cells must escape from immune surveillance in cancer metastasis $[19,20]$. DcR3 is a well-known immune suppressor [21, 22], and abnormally elevated DcR3 may help cancer cells metastasize by suppressing immune responses. However, whether DcR3 is valuable in differentiating cancer metastasis from non-metastasis remains largely unclear. In this study, we measured serum levels of DcR3 in several types of cancer and analyzed the correlation between DcR3 and hematological traits. Based on these observations, we further evaluated the value of DcR3 in detecting cancer metastasis in combination with hematological traits.

\section{RESULTS}

\section{Serum level of DcR3 was elevated in three types of human cancers}

To explore diagnostic application based on DcR3 expression, we established a sensitive ELISA to measure DcR3 serum levels $\left(11-12000 \mathrm{pg} / \mathrm{ml}, R^{2}=0.9941\right)$. The results showed significant elevations of DcR3 in gastric cancer $(2.04 \pm 1.01, P=0.0061)$, lymphoma $(1.62 \pm 0.75$, $P=0.041)$, and breast cancer $(1.53 \pm 0.51, P=0.023)$, but not in other cancers tested (Figure 1).

\section{ROC analysis suggested DcR3 was a valuable biomarker for identifying gastric cancer}

The data of serum concentrations of DcR3 were analyzed using the $\mathrm{R}$ package " $p R O C$." The results suggested high specificity, sensitivity, and accuracy for distinguishing gastric cancer patients from healthy controls (Figure 2A). Further analysis revealed that DcR3 was robust enough even to distinguish gastric cancer from other cancers (Figure 2B).

\section{DcR3 is associated with hematological traits}

ELISA and routine blood test data were organized and then analyzed using the Spearman correlation test. As analyzed in Figure 1, compared with healthy controls, many types of cancer had no significant differences in the serum DcR3 levels, of which metastatic cancers did. Because of the limited sample size for each individual type of cancer, we divided all of the cancer cases into metastatic and non-metastatic groups. Fifty-eight metastatic and Thirty-two non-metastatic cases were included. Clinical data of cancer patients are shown in Table 1. The results indicated that DcR3 was positively associated with PDW $\left(P=2.45 \times 10^{-6}, R=0.63\right)$ in subjects with metastatic cancers (Figure 3A). Additionally, DcR3 was found to be negatively associated with $\operatorname{HGB}(P=0.002, R=-0.59)$ and $\operatorname{HCT}(P=0.001, R=-0.62)$ in subjects with nonmetastatic cancers (Figure 3B, 3C). The correlations among PDW, HCT and HGB are shown in Supplementary Figure 2 .

\section{The combination of PDW, HGB, and HCT improves the detective ability of DcR3 for tumor metastasis}

The correlation analysis indicated that DcR3 was positively associated with PDW and negatively associated with HGB and HCT. Thus, to improve the diagnostic power of DcR3, we tried different mathematical combinations of DcR3, PDW, HGB and HCT, including Equation 1, Equation 2, Equation 3 and Equation 4. The results suggested the combination with best performance is the one shown in Equation 1. The novel indicator (specificity: $80.9 \%$, sensitivity: $75.0 \%$, AUC: $79.0 \%$ ) showed with better specificity, higher sensitivity, and greater accuracy than DcR3 alone (specificity: $70.2 \%$, sensitivity: $70.8 \%$, AUC: $69.1 \%$ ) (Figure 4). As shown in Table 2, the novel indicator was more strongly associated with metastatic risk (OR: $10.39,95 \%$ CI: 3.27-22.10). The results of ROCs and ORs of other Equations are shown in Supplementary Figure 1 and Supplementary Table 1.

The novel indicator $=\mathrm{DcR} 3 \times \mathrm{PDW} \div(\mathrm{HGB} \times \mathrm{HCT})$ Equation 1

\section{DISCUSSION}

Even in the face of the best currently available medical and surgical treatments, the overall prognosis of patients with metastatic cancers remains poor. In this study, we collected serum samples from patients with different caners and analyzed the DcR3 level. Results indicated an abnormal elevation of DcR3 in gastric cancer, lymphoma, and breast cancer. Results also suggested 
that DcR3 was a candidate biomarker for the highly specific and sensitive diagnosis of gastric cancer. Further investigation revealed that serum DcR3 was positively associated with PDW in metastatic cancers and negatively associated with HGB and HCT in non-metastatic cancers. The combined detection of DcR3, PDW, HGB, and HCT acts as a better biomarker than DcR3 alone with respect to differentiating cancer metastasis from non-metastasis.
Numerous studies have shown DcR3 expression to be markedly increased in metastatic cancers, such as esophageal cancer [23], gastric cancer [24], and colon cancer [25]. In a recent study, we found that DcR3 promoted hepatoma cell migration by down-regulating E-cadherin expression [10]. E-cadherin, a classical member of the cadherin superfamily, is a calcium-dependent cellcell adhesion glycoprotein that plays a key role in cellular

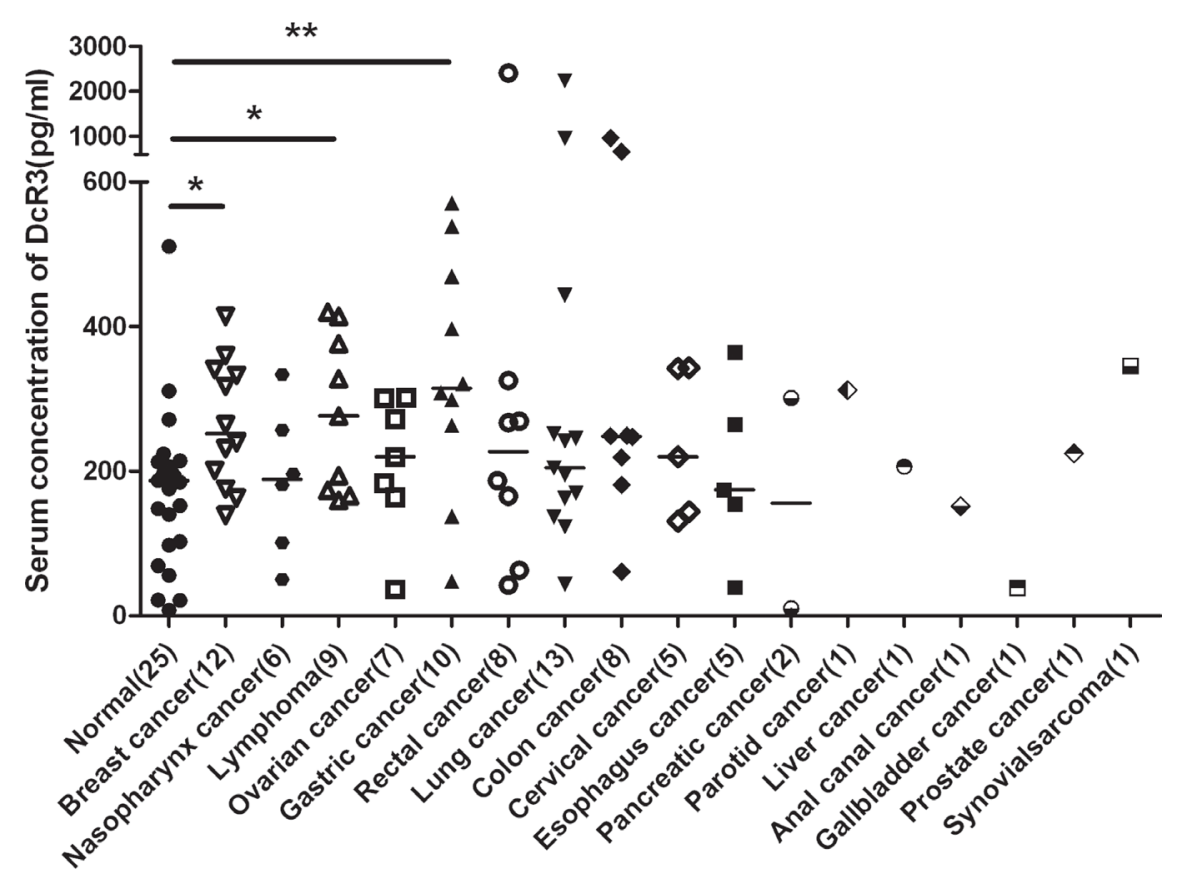

Figure 1: Serum DcR3 levels in cancer patients. DcR3 was significantly elevated in gastric cancer, lymphoma and breast cancer. Median DcR3 levels are indicated by short bars. The number of patients tested $(n)$ is shown. *compared with healthy controls, $P<0.05$. ${ }^{* *}$ compared with healthy controls, $P<0.01$.
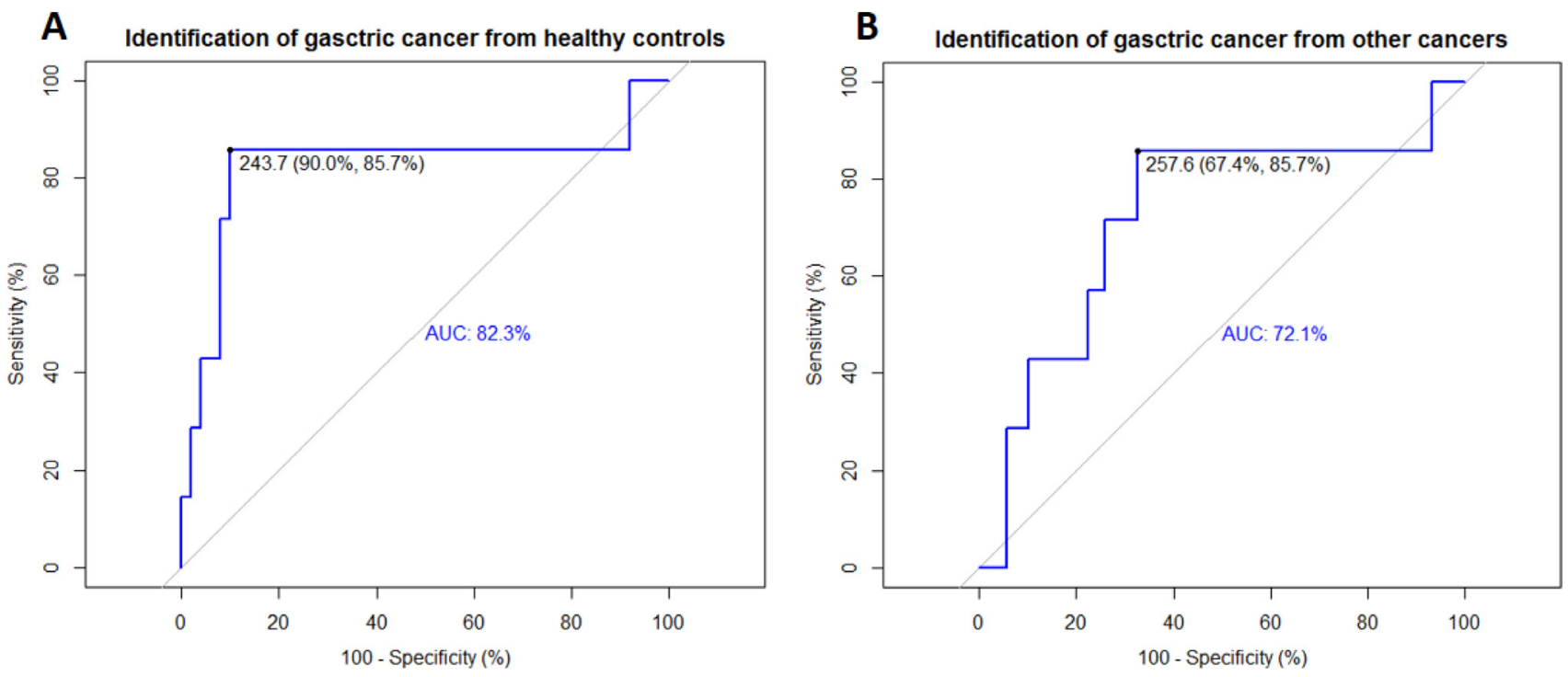

Figure 2: ROC curves revealed the diagnostic ability of DcR3 for gastric cancer. Identifications of gastric cancer from healthy controls and other cancers by DcR3 were evaluated using ROC curves. (A) Identification of gastric cancer from healthy controls using the ROC curve; sensitivity $=85.7 \%$, specificity $=90.0 \%, A U C=82.3 \%$, threshold $=243.7 \mathrm{pg} / \mathrm{mL} ;(\mathbf{B})$ Identification of gastric cancer from other cancers using the ROC curve; sensitivity $=85.7 \%$, specificity $=67.4 \%$, AUC $=72.1 \%$, threshold $=257.6 \mathrm{pg} / \mathrm{mL}$. 
Table 1: Clinical and laboratory characteristics of the participants

\begin{tabular}{|c|c|c|c|}
\hline Variables & $\begin{array}{c}\text { Metastasis } \\
(n=58)\end{array}$ & $\begin{array}{l}\text { Non-metastasis } \\
\quad(n=32)\end{array}$ & $P$-value \\
\hline Breast cancer $(n)$ & 9 & 3 & NA \\
\hline Lung cancer $(n)$ & 9 & 4 & NA \\
\hline Colon cancer $(n)$ & 6 & 2 & NA \\
\hline Gastric cancer $(n)$ & 7 & 3 & NA \\
\hline Rectal cancer $(n)$ & 5 & 3 & NA \\
\hline Lymphoma (n) & 3 & 6 & NA \\
\hline Ovarian cancer $(n)$ & 5 & 2 & NA \\
\hline Cervical cancer $(n)$ & 3 & 2 & NA \\
\hline Esophagus cancer $(n)$ & 3 & 2 & NA \\
\hline Nasopharynx cancer $(n)$ & 3 & 2 & NA \\
\hline Other cancers $(n)$ & 5 & 3 & NA \\
\hline Ages (years) & $51.5(12.2)$ & $47.4(15.5)$ & 0.102 \\
\hline Gender (males, \%) & $25(43.9)$ & $12(44.4)$ & 0.056 \\
\hline $\operatorname{DcR} 3(\mathrm{pg} / \mathrm{ml})^{*}$ & $335.6(413.6)$ & $228.5(173.7)$ & $<0.05$ \\
\hline PDW (\%) & $14.1(13.9)$ & $11.8(1.9)$ & 0.058 \\
\hline Haemoglobin $(\mathrm{g} / \mathrm{dl})^{*}$ & $112.2(24.1)$ & $124.5(16.7)$ & $<0.05$ \\
\hline Hematocrit $(\%)^{*}$ & $34.6(6.8)$ & $38.1(5.1)$ & $<0.05$ \\
\hline $\mathrm{DcR} 3 \times \mathrm{PDW} \div(\mathrm{HGB} \times \mathrm{HCT})^{* * *}$ & $1.4(1.9)$ & $0.4(0.2)$ & $<0.001$ \\
\hline
\end{tabular}

Data are presented as means(SD). $P$-Value was calculated by chi-square test (Age) or Mann-Whitney $U$ test. Metastasis includes lymph node metastasis and distant metastasis. The number of patients tested $(n)$ is shown.

"compared with non-metastatic cancers, $P<0.05$.

**** compared with non-metastatic cancers, $P<0.001$.

adhesion [26, 27]. The loss of E-cadherin function or expression has been implicated in cancer progression and metastasis $[28,29]$. In addition, DcR3 secreted by tumor cells is a negative regulator of MHC class II expression and a promoter of M2-like macrophage polarization (TumourAssociated Macrophages promotion) [21, 30]. Moreover, DcR3 protects tumor cells from apoptosis and chemotaxis, which in turn results in a decreased immune response to the TH2 phenotype [31, 32]. The immune suppressing ability of DcR3 may facilitate cancer cell metastasis, which also partially explains the correlation between DcR3 and cancer metastasis.

Previous studies have indicated that platelet activation plays a key role in cancer metastases [33, 34]. Platelet activation refers to, at least partially abnormally increased PDW, a measure of platelet heterogeneity determined by heterogeneous demarcation of megakaryocytes [35]. Tumors could regulate megakaryocytic maturation, platelet production, and platelet size through interleukin-6 (IL-6), macrophage colony stimulating factor (M-CSF), and granulocyte colony-stimulating factor (G-CSF) [36]. One significant finding suggests that IL-6 secreted from tumor cells promotes tumorigenesis, angiogenesis, and metastasis [37].
Additionally, G-CSF and M-CSF secreted by tumor cells may stimulate megakaryopoiesis and subsequent thrombopoiesis [38]. These analyses may explain why higher DcR3 levels are accompanied by higher PDW in cancer metastasis.

The current study suggests that a higher DcR3 level in non-metastatic cancers is associated with both lower HCT and lower HGB, which indicate anemia in patients. High DcR3 levels are associated with cancer malignant progression, which is a consequence of complex interactions between the host microenvironment and tumor cells [39]. Anemia provides about $50-60 \%$ of local solid tumors with hypoxic tissue, which might produce more aggressive tumor clones [40]. But in our study, one difference is that serum DcR3 level is not correlated with HGB and HCT in cancers with metastasis. The disorders may be caused by the change of pre-metastatic niche [41]. The underlying mechanisms still remain unclear and need further investigation.

The study has two limitations. Firstly, from this study, 58 metastatic and 32 non-metastatic cases as well as 25 controls are included, which is a relatively small sample size. Secondly, the participants are all Chinese. Thus, further studies are needed to be conduct for other ethnic groups. 
Our findings indicate that DcR3 is a potential biomarker for the detection of cancer cell metastasis across multiple cancer types; this biomarker could provide scientific clues for the evaluation and use of DcR3 in clinical diagnosis.

\section{MATERIALS AND METHODS}

\section{Collection of clinical samples}

The collection of human sera was approved by Ethics Committee of Shenzhen Second People's Hospital from January 2016 to December 2016. Informed consent was obtained from all patients and controls. All experiments using human blood samples were following the related technical and ethical guidelines. In our study, Sera from 90 tumor patients and 25 healthy individuals were collected during the same period. The mean age and age range at the time of diagnosis were 49 years and 24 to 92 years, respectively. Whole blood samples were collected in EDTA-containing tubes from the individuals with data on routine blood tests including platelet distribution width, hematocrit and hemoglobin, before initiating any treatment. All samples were processed within 30 min of blood collection.

\section{Cancers with metastasis Cancers without metastasis}
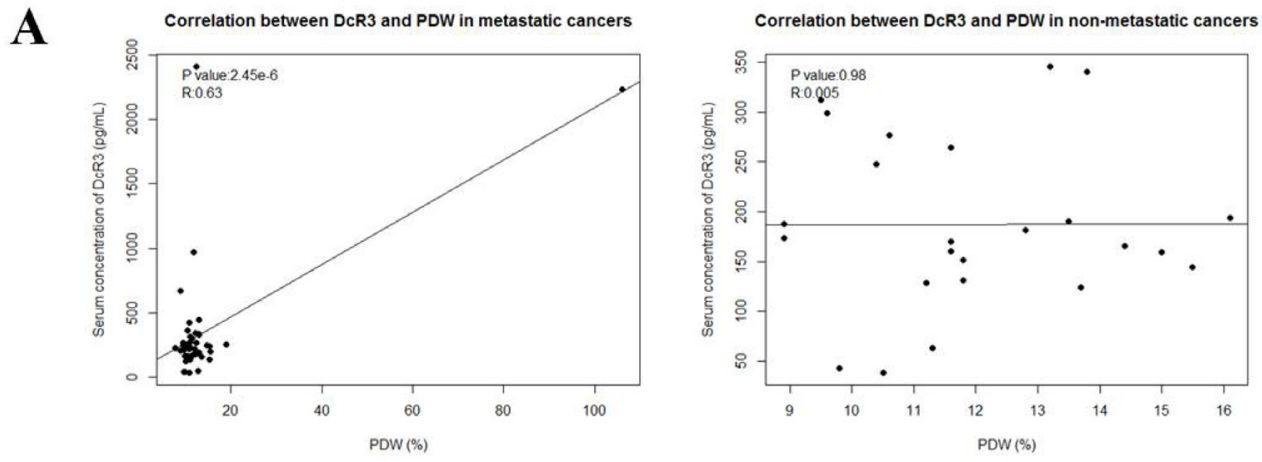

\section{$\operatorname{PDW}(\%)$}

B
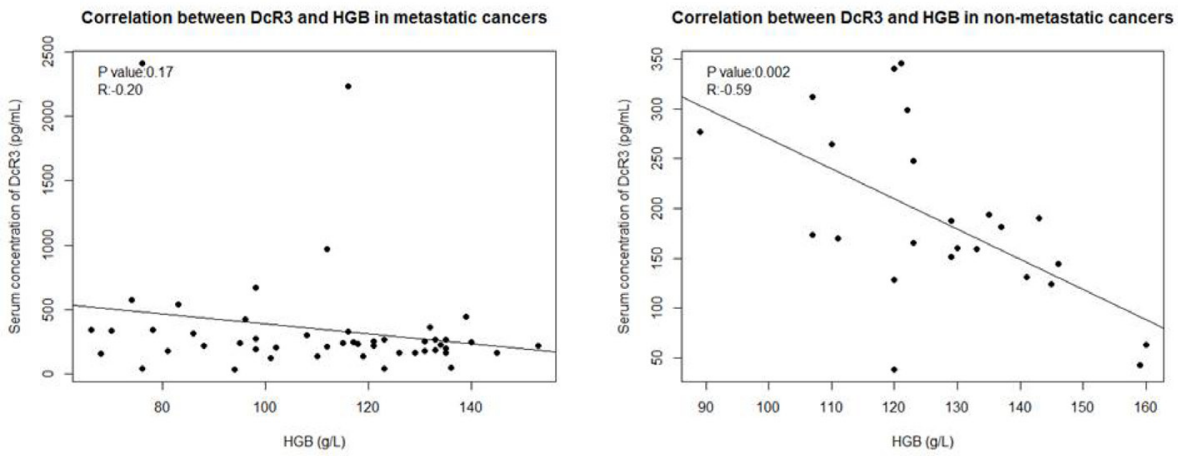

\section{$\operatorname{HGB}(\mathbf{g} / \mathbf{L})$}
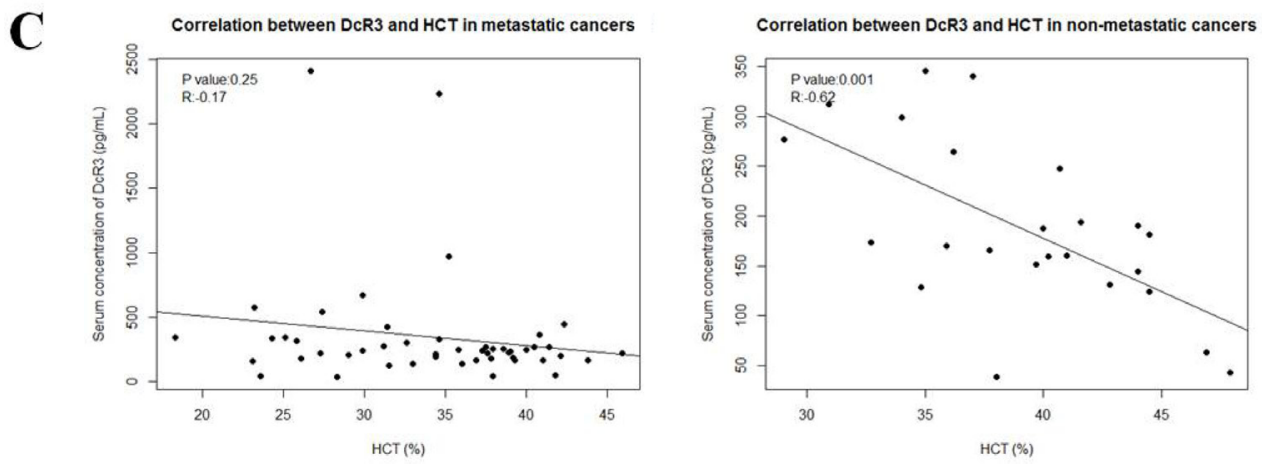

\section{HCT(\%)}

Figure 3: Correlations between serum DcR3 and hematological traits. Serum DcR3 level was associated with PDW, HGB and HCT. (A) Serum DcR3 level was positively correlated with PDW $\left(R=0.627, P=2.45 \times 10^{-6}\right)$ in metastatic cancers while not correlated with PDW $(R=0.0049, P=0.98)$ in non-metastatic cancers; (B) Serum DcR3 level was not correlated with HGB $(R=-0.20, P=0.17)$ in metastatic cancers while negatively correlated with $\operatorname{HGB}(R=-0.59, P=0.002)$ in non-metastatic cancers; $(\mathbf{C})$ Serum DcR3 level was not correlated with $\mathrm{HCT}(R=-0.17, P=0.25)$ in metastatic cancers while negatively correlated with $\mathrm{HCT}(R=-0.62, P=0.001)$ in nonmetastatic cancers. 


\section{Reagents}

The 96-well EIA/RIA high binding plates and bovine serum albumin (BSA) were bought from SigmaAldrich (Shanghai, China). Tris-buffered saline containing $0.05 \%$ Tween-20 (TBST), was acquired from double-helix (Shanghai, China). Tetramethylbenzidine dihydrochloride (TMB) and sulfuric acid were purchased from Sangon (Shanghai, China). Chinese hamster ovary cells, serumfree medium and spinner flasks were bought from Invitrogen (Carlsbad, CA, USA). The DcR3 ELISA kit was purchased from R\&D (Minneapolis, MN, USA).

\section{Generation of monoclonal antibodies against human DcR3}

Full-length human DcR3 cDNA fused to the sequence encoding the $\mathrm{Fc}$ domain of human IgG1 was here synthesized and cloned into a pcDNA3.1 expression vector (Invitrogen, Carlsbad, CA, USA). Chinese hamster ovary cells were transfected with this expression vector and grown in serum-free medium using a spinner flask. The soluble DcR3-Fc was purified from the medium and a panel of anti-DcR3 monoclonal antibodies against the recombinant protein was produced by hybridoma technology.

\section{Measurement of DcR3 using ELISA}

We paired two antibodies, 5C3 and 4E7, to serve as capture and detection antibodies in double-antibody sandwiched ELISA. These antibodies both selectively recognized soluble DcR3 with higher sensibility and wider linear range than the DcR3 ELISA kit purchased from R\&D (187-12000 pg/ml). Capture antibody was immobilized on the high binding plate. The plate was then blocked using $1 \%$ BSA. The plate was incubated with standards and serum samples at room temperature for $2 \mathrm{~h}$, washed in TBST and incubated with detection antibody at room temperature for another $2 \mathrm{~h}$. The plate was then sequentially incubated with streptavidin-HRP conjugations, $\mathrm{TMB}$, and $1 \mathrm{~mol} / \mathrm{L}$ of sulfuric acid. Data were recorded (at $450 \mathrm{~nm}$ ) using a M1000 (Tecan) plate reader.

\section{Statistical analysis}

Receiver operating characteristic (ROC) curve was used to analyze the classification power of candidate biomarkers. Pearson's test was used for correlation analysis between DcR3 and blood test indicators. The student's $t$ test was used to evaluate the statistical significance of the difference in DcR3 between metastatic and non-metastatic cancers. The odds ratio (OR) and 95\% confidence interval

\section{Combination with PDW,HGB and HCT improves the detective ability of DCR3 for tumor metastasis}

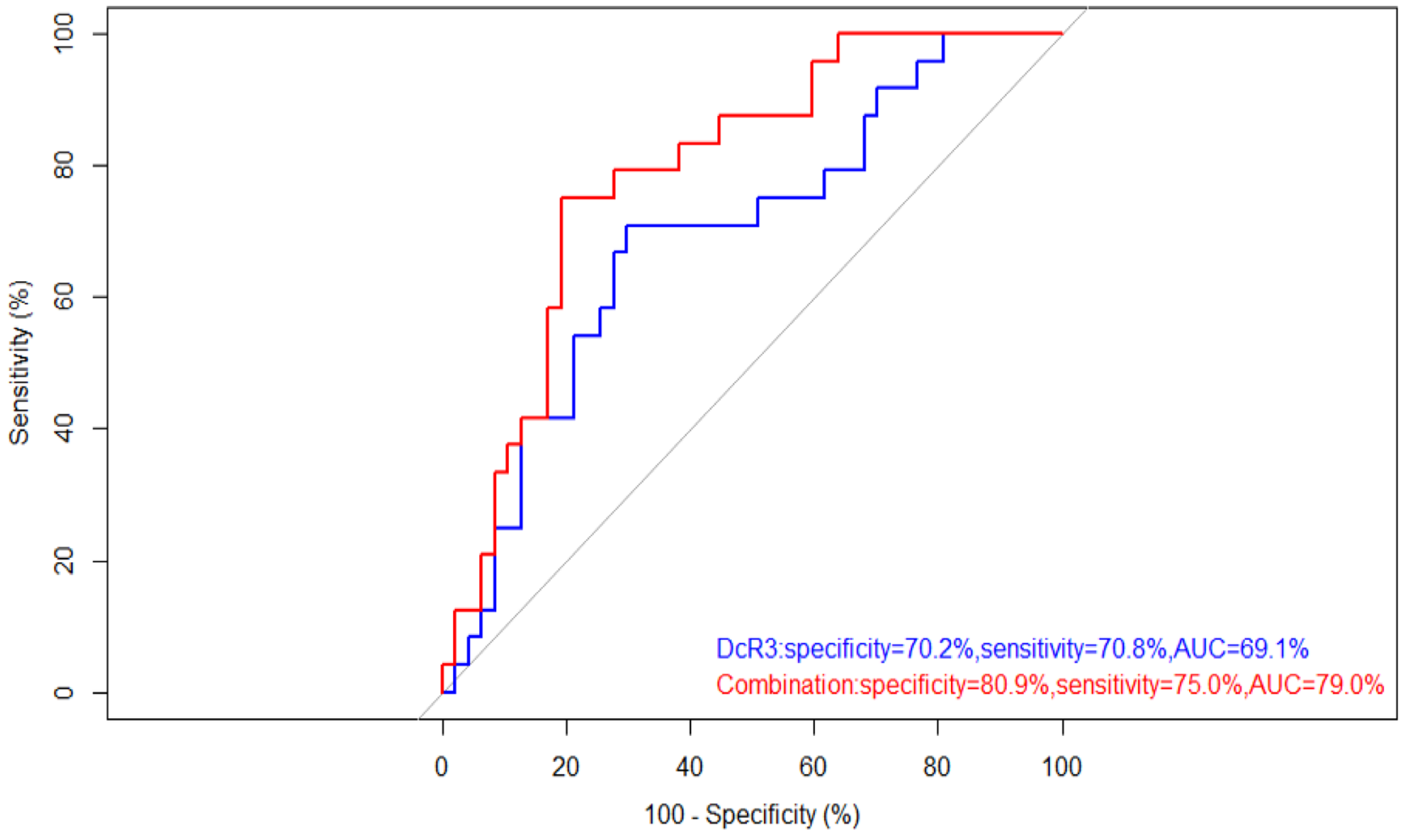

Figure 4: ROC curve showed the utility of alone or combination for the diagnosis of tumor metastasis. Combined use of PDW, HGB, HCT and DcR3 improves both specificity and sensitivity for the diagnosis of tumor metastasis. The thresholds of DcR3 alone and combination were $194.30 \mathrm{pg} / \mathrm{ml}$ and 0.54 , respectively. 
Table 2: Metastasis risk according to DcR3 and the novel indicator

\begin{tabular}{|c|c|c|c|c|c|c|c|c|}
\hline \multirow{2}{*}{ Parameter } & \multicolumn{4}{|c|}{ DcR3 (pg/ml) } & \multicolumn{4}{|c|}{ DcR3 $\times$ PDW $\div($ HGB $\times$ HCT $)$} \\
\hline & $>194.30$ & $<194.30$ & OR $(95 \% \mathrm{CI})$ & $P$-value & $>0.54$ & $<0.54$ & OR (95\% CI) & $P$-value \\
\hline $\begin{array}{l}\text { Metastasis } \\
(n=58)\end{array}$ & $n=44$ & $n=14$ & $\begin{array}{c}5.23 \\
(1.94-11.85)\end{array}$ & 0.001 & $n=49$ & $n=9$ & $\begin{array}{c}10.39 \\
(3.27-22.10)\end{array}$ & $2.17 \times 10^{-5}$ \\
\hline $\begin{array}{l}\text { Non-Metastasis } \\
(n=32)\end{array}$ & $n=12$ & $n=20$ & & & $n=11$ & $n=21$ & & \\
\hline
\end{tabular}

The number of patients tested $(n)$ is shown.

OR: Odds Ratio.

CI: Confidence Interval.

(95\% CI) were calculated using multivariate logistic regression analysis. The statistical analysis was performed using GraphPad Prism version 5.0 for Windows (GraphPad Software, San Diego, CA, USA).

\section{Ethics section}

The collection of human sera was approved by the Ethics Committee of Shenzhen Second People's Hospital. Informed consent was obtained from all patients and controls. All experiments using human blood samples were following the related technical and ethical guidelines.

\section{Abbreviations}

DcR3: Decoy receptor 3; PDW: Platelet Distribution Width; HGB: Haemoglobin; HCT: Hematocrit; ROC: Receiver Operating Characteristic; TMB: Tetramethylbenzidine Dihydrochloride; OR: Odds Ratio; 95\% CI: 95\% Confidence Interval; CEA: Carcino-Embryonic Antigen; AUC: Area Under Curve.

\section{Author contributions}

Xiaochun Wan and Youhai $H$. Chen designed the experiments; Junxin Li performed most of the experiments; Xiaohu Ren wrote the manuscript; Ni Xie and Jianhui Yuan revised the manuscript and collected serum samples; Lvyan Liu participated in monoclonal antibody preparation of DcR3; Qian Chen participated in measurement of DcR3 using ELISA; Qiming Zhou participated in routine blood tests; Guizhong Zhang and Qingguo Ruan performed statistical analysis.

\section{CONFLICTS OF INTEREST}

The authors declare no conflicts of interest.

\section{FUNDING}

This work was supported by Shenzhen Peacock Team Project [1110140040347265], the Fourth Batch of Talents Project in Guangdong Province [2014-1], the Nature Science Foundation of China [81373112], Shenzhen Special Funds of Industry in the Future [2015-971], Shenzhen Municipal Development and Reform Commission (NDRC) Engineering Laboratory Project [2014-1782], the Project of Guangdong Natural Science Foundation [2016A030310033], the Project of Shenzhen Basic Research Plan [JCYJ20150402102135491, JCYJ201603 28161613864], Shenzhen Technology Innovation Progect [JSGG20160229202150023， JSGG20140701164558078, and JCYJ20150330102720122], the Project of Shenzhen International Cooperation Foundation [GJHZ201603 01163138685, GJHZ20130412153906740], the Natural Science Foundation of Guangdong [2016A030313029], the Natural Science Foundation of China for Young Scholar Grant [81501356], and the Project of Guangdong Scientific Plan Foundation [2013A022100037, 2013B021800097, and 2014A020212038].

\section{REFERENCES}

1. Pitti RM, Marsters SA, Lawrence DA, Roy M, Kischkel FC, Dowd P, Huang A, Donahue CJ, Sherwood SW, Baldwin DT, Godowski PJ, Wood WI, Gurney AL, et al. Genomic amplification of a decoy receptor for Fas ligand in lung and colon cancer. Nature. 1998; 396:699-703. https:// doi.org/10.1038/25387.

2. Wu Y, Han B, Sheng H, Lin M, Moore PA, Zhang J, Wu J. Clinical significance of detecting elevated serum DcR3/ TR6/M68 in malignant tumor patients. Int J Cancer. 2003; 105:724-32. https://doi.org/10.1002/ijc.11138.

3. Liang C, Xu Y, Li G, Zhao T, Xia F, Li G, Zhang D, Wu J. Downregulation of DcR3 sensitizes hepatocellular carcinoma cells to TRAIL-induced apoptosis. Onco Targets Ther. 2017; 10:417-28. https://doi.org/10.2147/OTT.S127202.

4. Fu Z, Chen S, Liu S, Han S, Gao X, Li D, Li D. DcR3 gene polymorphisms are associated with sporadic breast infiltrating ductal carcinoma in Northeast Chinese women. Oncotarget. 2016; 7:57970-7. https://doi.org/10.18632/ oncotarget.11153.

5. Lin WW, Hsieh SL. Decoy receptor 3: a pleiotropic immunomodulator and biomarker for inflammatory diseases, 
autoimmune diseases and cancer. Biochem Pharmacol. 2011; 81:838-47. https://doi.org/10.1016/j.bcp.2011.01.011.

6. Simon I, Liu Y, Krall KL, Urban N, Wolfert RL, Kim NW, McIntosh MW. Evaluation of the novel serum markers B7-H4, Spondin 2, and DcR3 for diagnosis and early detection of ovarian cancer. Gynecol Oncol. 2007; 106:112-8. https://doi.org/10.1016/j.ygyno.2007.03.007.

7. Edfeldt K, Daskalakis K, Backlin C, Norlen O, Tiensuu Janson E, Westin G, Hellman P, Stalberg P. DcR3, TFF3 and Midkine are Novel Serum Biomarkers in Small Intestinal Neuroendocrine Tumors. Neuroendocrinology. 2017; 105:170-181. https://doi.org/10.1159/000452891.

8. Zhou J, Song S, Li D, He S, Zhang B, Wang Z, Zhu X. Decoy receptor 3 (DcR3) overexpression predicts the prognosis and pN2 in pancreatic head carcinoma. World J Surg Oncol. 2014; 12:52. https://doi.org/10.1186/1477-7819-12-52.

9. Wu Y, Guo E, Yu J, Xie Q. High DcR3 expression predicts stage pN2-3 in gastric cancer. Am J Clin Oncol. 2008; 31:79-83. https://doi.org/10.1097/COC.0b013e3180ca77ad.

10. Zhang H, Chen X, Li D, Cui L, Li X, Ye X, Wan X. DcR3 promotes hepatoma cell migration by downregulating E-cadherin expression. Oncol Rep. 2017; 38:377-83. https://doi.org/10.3892/or.2017.5685.

11. Kozak MM, von Eyben R, Pai JS, Anderson EM, Welton ML, Shelton AA, Kin C, Koong AC, Chang DT. The Prognostic Significance of Pretreatment Hematologic Parameters in Patients Undergoing Resection for Colorectal Cancer. Am J Clin Oncol. 2017; 40:405-412. https://doi. org/10.1097/COC.0000000000000183.

12. Song X, Zhu H, Pei Q, Tan F, Li C, Zhou Z, Zhou Y, Yu N, Li Y, Pei H. Significance of inflammation-based indices in the prognosis of patients with non-metastatic colorectal cancer. Oncotarget. 2017; 8:45178-45189. https://doi.org/ 10.18632/oncotarget.16774.

13. Zhang X, Cui MM, Fu S, Li LL, Liu YS, Liu ZP, Liu T, Wang RT, Yu KJ. Platelet distribution width correlates with prognosis of gastric cancer. Oncotarget. 2017; 8:20213-9. https://doi.org/10.18632/oncotarget.15561.

14. Yu YJ, Li N, Yun ZY, Niu Y, Xu JJ, Liu ZP, Liu T, Wang RT, Yu KJ. Preoperative mean platelet volume and platelet distribution associated with thyroid cancer. Neoplasma. 2017; 64:594-598. https://doi.org/10.4149/neo_2017_414.

15. Yun ZY, Li N, Zhang X, Zhang H, Bu Y, Sun Y, Liu T, Wang RT, Yu KJ. Mean platelet volume, platelet distribution width and carcinoembryonic antigen to discriminate gastric cancer from gastric ulcer. Oncotarget. 2017; 8:62600-62605. https://doi.org/10.18632/oncotarget.15898.

16. Chen B, Dai D, Tang H, Ai X, Chen X, Zhang X, Li Z, Xie X. Pretreatment Hematocrit Is Superior to Hemoglobin as a Prognostic Factor for Triple Negative Breast Cancer. PLoS One. 2016; 11:e0165133. https://doi.org/10.1371/journal. pone. 0165133 .

17. Schwartz RN. Anemia in patients with cancer: incidence, causes, impact, management, and use of treatment guidelines and protocols. Am J Health Syst Pharm. 2007; 64:S5-13; quiz S28-30. https://doi.org/10.2146/ajhp060601.

18. Smith RS, Chen Q, Hudson MM, Link MP, Kun L, Weinstein H, Billett A, Marcus KJ, Tarbell NJ, Donaldson SS. Prognostic factors for children with Hodgkin's disease treated with combined-modality therapy. J Clin Oncol. 2003; 21:2026-33. https://doi.org/10.1200/jco.2003.07.124.

19. Dunn GP, Bruce AT, Ikeda H, Old LJ, Schreiber RD. Cancer immunoediting: from immunosurveillance to tumor escape. Nat Immunol. 2002; 3:991-8. https://doi.org/10.1038/ ni1102-991.

20. Kitamura T, Qian BZ, Pollard JW. Immune cell promotion of metastasis. Nat Rev Immunol. 2015; 15:73-86. https:// doi.org/10.1038/nri3789.

21. Chang YC, Chen TC, Lee CT, Yang CY, Wang HW, Wang $\mathrm{CC}$, Hsieh SL. Epigenetic control of MHC class II expression in tumor-associated macrophages by decoy receptor 3 . Blood. 2008; 111:5054-63. https://doi.org/10.1182/ blood-2007-12-130609.

22. You RI, Chang YC, Chen PM, Wang WS, Hsu TL, Yang CY, Lee CT, Hsieh SL. Apoptosis of dendritic cells induced by decoy receptor 3 (DcR3). Blood. 2008; 111:1480-8. https:// doi.org/10.1182/blood-2007-09-114850.

23. Ao R, Du YQ, Wang Y, Chen YS, Wang BY. MMP-2 and DcR3 expression in esophageal cancer tissue and correlation with patient survival. Int J Clin Exp Med. 2013; 6:700-5.

24. Zheng XF, Miao LY, Li S, Wang YB. Promotive Effects of Dcr3 Gene on the Occurrence and Progression of Gastric Cancer and its Mechanism. Hepatogastroenterology. 2014; 61:880-4.

25. Yu W, Xu YC, Tao Y, He P, Li Y, Wu T, Zhu YP, Li J, Wu JX, Dai J. DcR3 regulates the growth and metastatic potential of SW480 colon cancer cells. Oncol Rep. 2013; 30:2741-8. https://doi.org/10.3892/or.2013.2769.

26. Ishiyama N, Lee SH, Liu S, Li GY, Smith MJ, Reichardt LF, Ikura M. Dynamic and static interactions between p120 catenin and E-cadherin regulate the stability of cell-cell adhesion. Cell. 2010; 141:117-28. https://doi.org/10.1016/j. cell.2010.01.017.

27. Benham-Pyle BW, Pruitt BL, Nelson WJ. Cell adhesion. Mechanical strain induces E-cadherin-dependent Yap1 and beta-catenin activation to drive cell cycle entry. Science. 2015; 348:1024-7. https://doi.org/10.1126/science.aaa4559.

28. Perl AK, Wilgenbus P, Dahl U, Semb H, Christofori G. A causal role for E-cadherin in the transition from adenoma to carcinoma. Nature. 1998; 392:190-3. https://doi. org/10.1038/32433.

29. Nagafuchi A, Shirayoshi Y, Okazaki K, Yasuda K, Takeichi M. Transformation of cell adhesion properties by exogenously introduced E-cadherin cDNA. Nature. 1987; 329:341-3. https://doi.org/10.1038/329341a0.

30. Marchesi M, Andersson E, Villabona L, Seliger B, Lundqvist A, Kiessling R, Masucci GV. HLA-dependent tumour development: a role for tumour associate 
macrophages? J Transl Med. 2013; 11:247. https://doi. org/10.1186/1479-5876-11-247.

31. Hsu TL, Wu YY, Chang YC, Yang CY, Lai MZ, Su WB, Hsieh SL. Attenuation of Th1 response in decoy receptor 3 transgenic mice. J Immunol. 2005; 175:5135-45.

32. Ge Z, Sanders AJ, Ye L, Jiang WG. Aberrant expression and function of death receptor-3 and death decoy receptor-3 in human cancer. Exp Ther Med. 2011; 2:167-72. https://doi. org/10.3892/etm.2011.206.

33. Li N. Platelets in cancer metastasis: To help the "villain" to do evil. Int J Cancer. 2016; 138:2078-87. https://doi. org/10.1002/ijc.29847.

34. Goubran HA, Stakiw J, Radosevic M, Burnouf T. Plateletcancer interactions. Semin Thromb Hemost. 2014; 40:296-305. https://doi.org/10.1055/s-0034-1370767.

35. Paulus JM. Recent advances in the story of megakaryocyte physiology. Pathol Biol (Paris). 1981; 29:133-5.

36. Kaushansky K. Growth factors and hematopoietic cell fate. A new feature: controversies in hematology. Blood. 1998; 92:345-4.

37. Kumari N, Dwarakanath BS, Das A, Bhatt AN. Role of interleukin-6 in cancer progression and therapeutic resistance. Tumour Biol. 2016; 37:11553-72. https://doi. org/10.1007/s13277-016-5098-7.

38. Kowanetz M, Wu X, Lee J, Tan M, Hagenbeek T, Qu X, Yu L, Ross J, Korsisaari N, Cao T, Bou-Reslan H, Kallop D, Weimer R, et al. Granulocyte-colony stimulating factor promotes lung metastasis through mobilization of Ly6G+Ly6C+ granulocytes. Proc Natl Acad Sci U S A. 2010; 107:21248-55. https://doi.org/10.1073/pnas.1015855107.

39. Liotta LA, Kohn EC. The microenvironment of the tumourhost interface. Nature. 2001; 411:375-9. https://doi. org/10.1038/35077241.

40. Szkandera J, Gerger A, Liegl-Atzwanger B, Stotz M, Samonigg H, Ploner F, Stojakovic T, Leithner A, Pichler M. Pre-treatment anemia is a poor prognostic factor in soft tissue sarcoma patients. PLoS One. 2014; 9:e107297. https://doi.org/10.1371/journal.pone.0107297.

41. Kaplan RN, Riba RD, Zacharoulis S, Bramley AH, Vincent L, Costa C, MacDonald DD, Jin DK, Shido K, Kerns SA, Zhu Z, Hicklin D, Wu Y, et al. VEGFR1-positive haematopoietic bone marrow progenitors initiate the premetastatic niche. Nature. 2005; 438:820-7. https://doi. org/10.1038/nature04186. 